Article

\title{
The Preparations and Water Vapor Barrier Properties of Polyimide Films Containing Amide Moieties
}

\author{
Kai Zhang, Qiaoxi Yu, Longji Zhu, Siwei Liu, Zhenguo Chi, Xudong Chen, Yi Zhang * and \\ Jiarui Xu \\ PCFM Lab, GD HPPC Lab, Guangdong Engineering Technology Research Centre for High-performance Organic \\ and Polymer Photoelectric Functional Films, State Key Laboratory of Optoelectronic Materials and Technologies, \\ School of Chemistry, Sun Yat-sen University, Guangzhou 510275, China; zhangk27@mail2.sysu.edu.cn (K.Z.); \\ yuqx3@mail2.sysu.edu.cn (Q.Y.); zhulj3@mail2.sysu.edu.cn (L.Z.); liusiw@mail.sysu.edu.cn (S.L.); \\ chizhg@mail.sysu.edu.cn (Z.C.); cescxd@mail.sysu.edu.cn (X.C.); xjr@mail.sysu.edu.cn (J.X.) \\ * Correspondence: ceszy@mail.sysu.edu.cn; Tel.: +86-020-8411-2222
}

Received: 23 September 2017; Accepted: 29 November 2017; Published: 5 December 2017

\begin{abstract}
Flexible displays are a systematic revolution in the field of display, in which high-performance and high-barrier polymer substrates are considered to be one of the most important key materials. In this work, high water vapor barrier polyimides containing amide moieties were synthesized via the ternary polymerization of 4,4'-diaminobenzailide (DABA), 4,4'-diaminodipheny ether (ODA), and 3,3',4,4'-biphenyl-tetracarboxylic acid dianhydride (BPDA) followed by thermal imidization. The relationship between the content of amide moieties and the water vapor barrier property of the prepared polyimides was studied by means of density test, water absorbing test, water contact angle test, water vapor permeation test, fourier transform infrared spectroscopy (FT-IR), thermogravimetric analysis (TGA), thermogravimetry coupled with fourier transform infrared spectrometry (TG-FTIR), wide-angle X-ray diffraction analysis (WXRD), mechanical performance test, etc. The results show that the introduction of amide groups into polyimide (PI) main chains can improve the water vapor barrier properties of the polyimides effectively. The water vapor transmission rate (WVTR) of the polyimide films can be improved from $8.2365 \mathrm{~g} \cdot\left(\mathrm{m}^{2} \cdot 24 \mathrm{~h}\right)^{-1}$ to $0.8670 \mathrm{~g} \cdot\left(\mathrm{m}^{2} \cdot 24 \mathrm{~h}\right)^{-1}$ with the increasing content of amide moieties.
\end{abstract}

Keywords: polyimides; water vapor barrier property; amide moieties; “locking water" effect

\section{Introduction}

The leading development trend of modern electronic products is miniaturization, integration, and portability [1,2]. Among them, flexible display is one of the most compelling systematic revolution technologies. High-performance polymer-based flexible substrates-especially high-barrier polymer substrates-are considered to be one of the most important key materials. They play important roles in the environmental protection and mechanical support for the devices [3-10], and are one of the main factors affecting the lifetime of devices [11-16]. The requirements of barrier properties of materials used in different fields are shown in Figure 1. Traditional polymer-based barrier materials are low-cost, good flexibility, light-weight, impact resistant, and require simple processing, and are widely used in the field of electronic encapsulation [17-25]. Among the traditional polymer-based substrates (Table 1), polyimides are widely used as electronic packaging and electrical insulation materials in the field of aerospace industries and microelectronics [26-28]. They are considered to be the most promising candidates for the flexible substrates of flexible displays because they are thermally stable under high processing temperature. However, the existence of free volume in polymer materials makes them essentially permeable [29-36], thus limiting their applications as barrier materials in the field of flexible 
displays. To address this, how to effectively reduce the free volume of the polymer and decrease the diffusion rate of water molecules in the polymer become key scientific questions in the field.

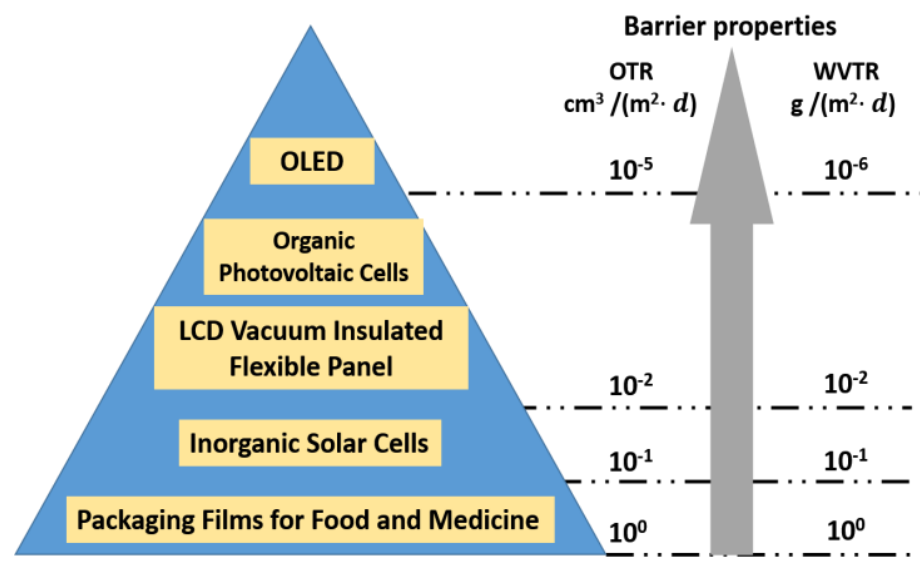

Figure 1. Requirements of products on the barrier performance of barrier materials. OLED: organic light-emitting diode; LCD: liquid-crystal display; WVTR: water vapor transmission rate; OTR: oxygen transmission rate.

Table 1. Water vapor permeation of common commercial barrier polymers [37].

\begin{tabular}{cccc}
\hline Company & Model & Type & $\begin{array}{c}\text { WVTR } \\
\mathbf{( 5 0} \mathbf{\mu m}) \mathbf{g} \cdot\left(\mathbf{m}^{\mathbf{2}} \cdot \mathbf{2 4} \mathbf{h}\right)^{\mathbf{- 1}}\end{array}$ \\
\hline uPont & Kapton & Polyimide(PI) Film & 27 \\
UBE & Upilex R & PI Film & 11.2 \\
Sabic Innovative Plastics & Ultem 1000 & Polyetherimide (PEI) Film & 60 \\
Dow Chemical & Trycite Oriented & Polystyrene(PS) Film & 70 \\
Teijin & Mylar & Polyethylene terephthalate(PET) & 10.6 \\
EMS Chemie & Grivory G21 & Film & 7 \\
Chevron Phillips & Ryton & Polyphenylene sulfide(PPS) Films & 6 \\
\hline
\end{tabular}

In this work, polyimides containing amide moieties were designed and prepared by solution copolymerization of 4,4'-diamino benzanilide (DABA), 4,4'-diaminodiphenyl ether (ODA) and $3,3^{\prime}, 4,4^{\prime}$-biphenyltetracarboxylic dianhydride (BPDA). Since the amide moieties contain both carbonyl and secondary amine groups, it is easy for them to form hydrogen bonds with hydroxyl groups, amino groups, and other polar groups. On one hand, amide moieties in the polymer backbone may enhance the intermolecular interactions by the formation of hydrogen bonds, which can reduce the free volume of polymers, and thus is beneficial to improve its barrier properties. On the other hand, the formation of hydrogen bond interactions between the amide moieties and the water molecules would contribute to reducing the diffusion rate of water vapor molecules in polymer materials, which also helps to enhance the water vapor barrier properties of the materials [38-40]. To investigate these interactional mechanisms, Fourier transform infrared spectroscopy (FT-IR), thermogravimetric analysis (TGA), and thermogravimetry coupled with fourier transform infrared spectrometry (TG-FTIR) were used to characterize the hydrogen bond interactions between the polymer segments and water molecules, and the "locked-water effect" of the amide moieties was proposed. FT-IR, TGA, TG-FTIR, wide-angle X-ray diffraction analysis (WXRD), water absorbing test, water contact angle test, mechanical performance test, and water vapor permeation test were also used to characterize the structure and properties of the polyimides. 


\section{Materials and Methods}

\subsection{Materials}

4,4'-Diamino benzanilide (DABA) and 4,4'-diaminodiphenyl ether (ODA) purchased from Alfa-Aesar (Shanghai, China) were used as-received. 3,3' ,4,4'-Biphenyltetracarboxylic dianhydride (BPDA) purchased from Shanghai GuChuang New Chemical Materials Co., Ltd. (shanghai, China) was used as-received. $\mathrm{N}, \mathrm{N}$-Dimethylformamide (DMF) was provided by Guangzhou Chemical Reagent Factory (Guangzhou, China).

\subsection{Synthesis of Poly(Amic Acid) Copolymers and Preparations of PI Films}

A representative example of synthesizing poly(amic acid) (PAA) copolymer was described as follows, where the mole ratio of DABA to ODA is 5:5, and the sample is marked as 5O5DPAA. Monomer-grade diamines, DABA (2.2985 g, $10.1 \mathrm{mmol})$ and ODA $(2.0251 \mathrm{~g}, 10.1 \mathrm{mmol})$, were added into a dry argon-flushed round-bottom flask. After the diamines had completely dissolved in anhydrous DMF $(50 \mathrm{~mL})$ by mechanical stirring at $25^{\circ} \mathrm{C}$, dianhydride monomer BPDA (6.0704 g, $20.06 \mathrm{mmol}$ ) was added into the solution in three batches. After the reaction had proceeded for $6-7 \mathrm{~h}$, viscous 5O5DPAA solution was obtained with a solid content of $18 \mathrm{wt} \%$. The PAA was subsequently coated uniformly on a clean and dry glass plate with a controlled film thickness, and then underwent a thermal imidization process in a vacuum oven with temperature program of $100{ }^{\circ} \mathrm{C}(1 \mathrm{~h}) / 200{ }^{\circ} \mathrm{C}$ $(1 \mathrm{~h}) / 300{ }^{\circ} \mathrm{C}(1 \mathrm{~h})$ to produce the final polyimide 5O5DPI. The polyimide film was removed from the glass substrate after the oven cooled to room temperature. Other polyimide films with different diamine ratios (ODA:DABA = 10:0, 7:3, 3:7, 0:10) were prepared in the same way, and were marked as OPI, 7O3DPI, 3O7DPI, and DPI.

\subsection{Methods}

FT-IR spectra were recorded on a Fourier transform infrared spectrometer (Nexus 670, Nicolet, WI, USA) from $4000 \mathrm{~cm}^{-1}$ to $400 \mathrm{~cm}^{-1}$ using attenuated total reflection (ATR) mode to characterize the chemical structure of the polyimide films. WXRD experiments were performed on a SmartLab LIFM-X (Rigaku, Tokyo, Japan) with a copper target tube and a two-dimensional detector. The X-ray beam was monochromatized to $\mathrm{Cu} K \alpha$ radiation $(\lambda=1.54 \AA)$ and the $\mathrm{X}$-ray generator was operated at $40 \mathrm{kV}$ and $30 \mathrm{~mA}$. The $2 \theta$ ranged from $5^{\circ}$ to $40^{\circ}$. The drainage method was used to measure the density of the dry PI films at room temperature. Before the test, the polyimide films were placed in an oven and heated to $300{ }^{\circ} \mathrm{C}$ with a $24 \mathrm{~h}$ isotherm to remove residual moisture from the films. An optical contact angle measuring instrument (DSA100, Kruss, Hamburg, Germany) was used to detect the hydrophilicity of the polyimide films, and the volume of water drop was $2 \mu \mathrm{L}$. The water absorption test method was as follows: dry films were weighed by electronic analytical balance to get the mass $M_{1}$, and then the dry films were immersed in deionized water for $168 \mathrm{~h}$ to make the films saturated with water. The surface was wiped and the films were weighed to get the mass $M_{2}$; then, the water absorption of the film could be obtained by $\left(M_{2}-M_{1}\right) / M_{1} \times 100 \%$. Thermal properties were determined through thermogravimetric analysis (TG-Q50, TA Instruments, New Castle, DE, USA). TGA was carried out from $50{ }^{\circ} \mathrm{C}$ to $900{ }^{\circ} \mathrm{C}$ at a heating rate of $20^{\circ} \mathrm{C} / \mathrm{min}$ under $\mathrm{N}_{2}$. A TG-FTIR interconnection instrument (TG-209, Netzsch, Freistaat Bayern, Germany/Vector-22, Brucker, Billerica, Germany) was used to identify the composition of volatile at a heating rate of $20^{\circ} \mathrm{C} / \mathrm{min}$ under $\mathrm{N}_{2}$. The mechanical properties were determined on a CMT6103 mechanical measuring instrument (SANS, Shenzhen, China) at a drawing rate of $10 \mathrm{~mm} / \mathrm{min}$, the samples were $10 \mathrm{~mm}$ in length and $100 \mathrm{~mm}$ in width. The water vapor transmission rates (WVTRs) were measured using a permeation test system (W3/330, Labthink, Ji'nan, China) at $37.8{ }^{\circ} \mathrm{C}$ and $85 \%$ relative humidity (RH). 


\section{Results and Discussion}

\subsection{Synthesis and Characteristics of the Polyimide Films}

The amide-containing polyimides were synthesized using a two-step method by the copolymerization of ODA and BPDA with an amide-containing diamine DABA, as shown in Scheme 1. The poly(amic acid)s were synthesized by gradually adding the dianhydride monomer into the anhydrous DMF solution of diamines, and stirred for $6-7 \mathrm{~h}$ at $25^{\circ} \mathrm{C}$. Thermal imidization procedures were chosen to form polyimides. The chemical structure of the polyimide films was investigated by FT-IR, and the results are shown in Figure 2. The polyimide films exhibited characteristic absorption peaks of imide ring at around $1779 \mathrm{~cm}^{-1}$ ( $\mathrm{C}=\mathrm{O}$ asymmetrical stretching vibration), $1725 \mathrm{~cm}^{-1}$ ( $\mathrm{C}=\mathrm{O}$ symmetrical stretching vibration), $1380 \mathrm{~cm}^{-1}$ (C-N stretching vibration), and $758 \mathrm{~cm}^{-1}$ (imide ring deformation). These demonstrate that all of the poly(amic acid)s were fully converted into polyimides by the thermal imidization process. When DABA was added, the polyimide films exhibited characteristic absorption peaks at $1651 \mathrm{~cm}^{-1}$ ("Amide I", $\mathrm{C}=\mathrm{O}$ stretching vibration in amide), $1514 \mathrm{~cm}^{-1}$ ("Amide II", C-N-H bending vibration), and $1308 \mathrm{~cm}^{-1}$ ("Amide III", the mix of $\mathrm{C}-\mathrm{N}$ stretching vibration and $\mathrm{N}-\mathrm{H}$ bending vibration). This indicated that the synthesized polyimide had characteristics of both imide and amide groups. Additionally, the absorption peak intensity of the peaks at $1651 \mathrm{~cm}^{-1}$ and $1308 \mathrm{~cm}^{-1}$ increased with the increase of DABA content.

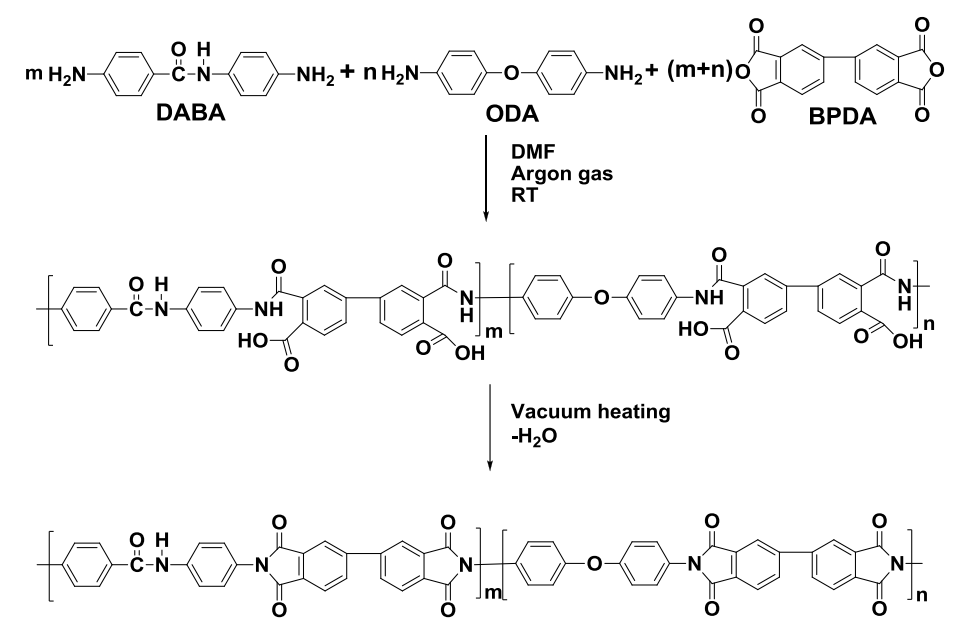

Scheme 1. Scheme of the synthesis of polyimide containing amide moieties. BPDA: 3,3',4,4'biphenyltetracarboxylic dianhydride; DABA: 4,4'-diamino benzanilide; ODA: 4,4'-diaminodiphenyl ether. DMF: N,N-Dimethylformamide; RT: room temperature.

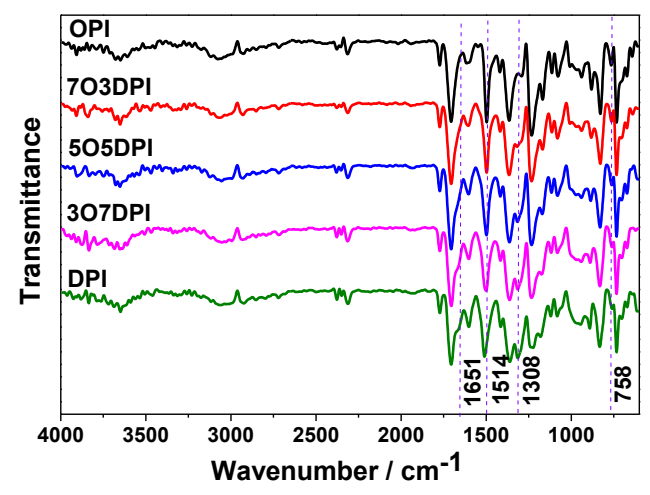

Figure 2. Fourier transform infrared (FT-IR) spectra of the polyimide films. OPI refers to a polyimide film where ODA:DABA = 10:0; 7O3DPI a film where ODA:DABA = 7:3; 5O5DPI a film where ODA:DABA = 5:5; 3O7DPI a film where ODA:DABA = 3:7; DPI a film where ODA:DABA = 0:10. 


\subsection{Aggregation Structures and Density of the Polyimide Films}

The aggregation state of the polyimide films was characterized by WXRD with graphite monochromatized $\mathrm{Cu} \mathrm{K} \alpha$ radiation, $2 \theta$ ranging from $0^{\circ}$ to $40^{\circ}$, and the results are shown in Figure 3 . The X-ray diffraction curves of the polyimide films express a set of wider diffraction peaks in the range of $10^{\circ}$ to $33^{\circ}$. With the increase in DABA content, the intensity of the diffraction peaks increased and the shape become sharper, which meant that the order of the polyimide macro-molecular chain arrangement increased. The reason for this may be due to the existence of the amide-group in the polymer main chain, which is conducive to the formation of inter-molecular hydrogen bond interactions, thus enhancing the inter-molecular interactions to form more ordered and compact macromolecular chain arrangements.

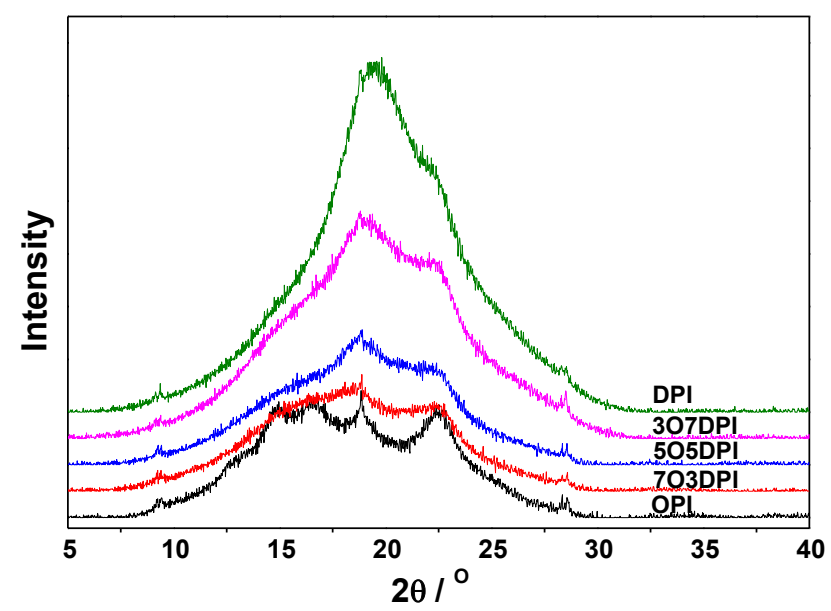

Figure 3. Wide-angle X-ray diffraction (WXRD) spectrum of the polyimide films.

The density of the polyimide films was measured by the drainage method, and the results are shown in Figure 4 . The density of the polyimide without DABA moiety (OPI) was $1.4099 \pm 0.0032 \mathrm{~g} / \mathrm{cm}^{3}$. With the increase of DABA content, the density of polyimide film increased, from $1.4316 \pm 0.0007 \mathrm{~g} / \mathrm{cm}^{3}$ (7O3DPI) to $1.4720 \pm 0.0046 \mathrm{~g} / \mathrm{cm}^{3}$ (DPI). The density increased by $16.9 \%$ when the diamine ODA was completely replaced by DABA. Combined with the WXRD results, it is obvious that the increase in density may be due to the closest packing of the macromolecules caused by the inter-molecular hydrogen bonding interaction.

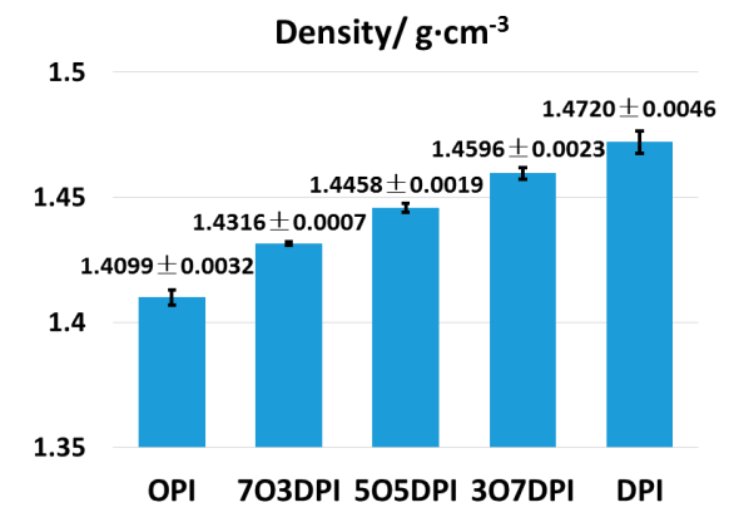

Figure 4. Density data of the polyimide films. 


\subsection{Surface Hydrophilicity and Water Absorption Properties of the Polyimide Films}

The introduction of the amide moiety into the polyimide backbone increases the molecular polarity of the prepared polyimides, which will have an effect on the surface polarity and water absorption capacity of the polymer. The hydrophilicity of the polyimide films was measured by an optical contact angle measuring instrument. The results in Figure 5 and Table 2 show that all the polyimide films exhibited certain hydrophilic properties. The surface water contact angle obviously decreased with the increase of the DABA content, ranging from $79.4^{\circ}$ (OPI) to $64.7^{\circ}$ (DPI). This means that the increase of the polar amide groups in the polyimide backbone resulted in the hydrophilic enhancement of the surface.

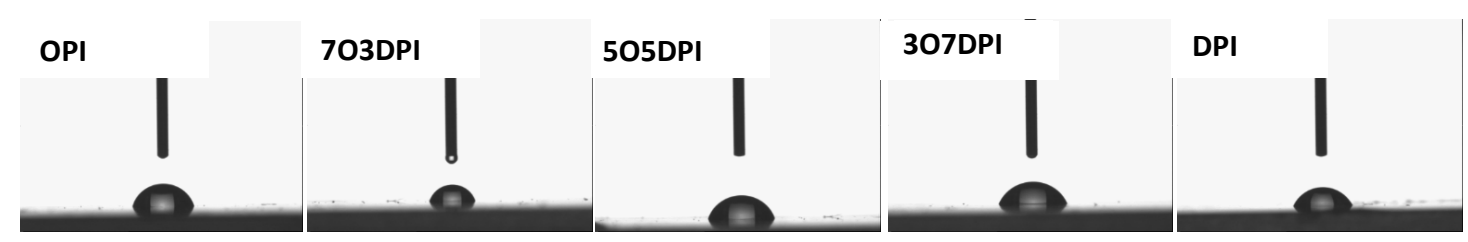

Figure 5. Images of water contact angle test of polyimide films.

Before the water absorption test, the polyimide films were placed in a vacuum oven at $300{ }^{\circ} \mathrm{C}$ for $24 \mathrm{~h}$ to ensure that the films were completely dry. The dried films were weighed by an electronic analytical balance to get the mass $M_{1}$. Then, the dry films were immersed in deionized water for 168 $\mathrm{h}$ to make sure the polyimide films were fully absorbent and saturated with water. Then, the film surface was wiped and the film was weighed to get the mass $M_{2}$. The water absorption of the film can be calculated by the equation $\left(M_{2}-M_{1}\right) / M_{1} \times 100 \%$. The results are shown in Table 2 . As can be seen, the water absorption of polyimide films increased dramatically with the increase of the DABA content, from $0.7998 \%$ (OPI) to $3.6327 \%$ (DPI). As it is known that the amide groups in the polymer main chain can easily form hydrogen bonds with water molecules, so the water absorption capacities of the polymers enhanced.

Table 2. Water absorption and water contact angle of the polyimide films.

\begin{tabular}{ccccc}
\hline Sample & $\boldsymbol{M}_{\mathbf{1}} / \mathbf{g}$ & $\boldsymbol{M}_{\mathbf{2}} / \mathbf{g}$ & Water absorption/\% & Water contact angle $/^{\circ}$ \\
\hline OPI & 0.6001 & 0.6049 & 0.7998 & 79.4 \\
7O3DPI & 0.3065 & 0.3112 & 1.5334 & 75.3 \\
5O5DPI & 0.2563 & 0.2618 & 2.1459 & 72.7 \\
3O7DPI & 0.3072 & 0.3154 & 2.6693 & 68.1 \\
DPI & 0.2505 & 0.2596 & 3.6327 & 64.7 \\
\hline
\end{tabular}

\subsection{Mechanical Properties of the Polyimide Films}

The mechanical properties of the polyimide films were tested on an electronic universal testing machine. The results are shown in Table 3. All polyimide films exhibit excellent mechanical properties. The tensile strength of OPI film is $136.8 \pm 4.7 \mathrm{MPa}$, the elastic modulus is $3.20 \pm 0.51 \mathrm{GPa}$, and the elongation at break is $14.4 \pm 2.3 \%$. With the increase of the DABA fraction in the polymer backbone, the tensile strength and elastic modulus increased, and when all the ODA was replaced by DABA, they reached $174.3 \pm 0.6 \mathrm{MPa}$ and $4.08 \pm 0.29 \mathrm{GPa}$, respectively. However, the elongation at break decreased from $14.4 \%$ to $9.8 \%$. Obviously, although the introduction of rigid DABA components will have a certain impact on the flexibility of the materials, they are beneficial to improve their mechanical strength. 
Table 3. Mechanical properties of the polyimide films.

\begin{tabular}{cccc}
\hline Sample & Tensile strength/MPa & Elongation at break/\% & Elastic modulus/GPa \\
\hline OPI & $136.8 \pm 4.7$ & $14.4 \pm 2.3$ & $3.20 \pm 0.51$ \\
7O3DPI & $140.2 \pm 4.5$ & $12.6 \pm 1.3$ & $3.58 \pm 0.38$ \\
5O5DPI & $152.7 \pm 4.3$ & $12.5 \pm 1.1$ & $3.65 \pm 0.49$ \\
3O7DPI & $165.4 \pm 6.4$ & $11.0 \pm 2.4$ & $3.66 \pm 0.30$ \\
DPI & $174.3 \pm 0.6$ & $9.8 \pm 1.6$ & $4.08 \pm 0.29$ \\
\hline
\end{tabular}

Hedenqvist proved that water can affect the structure of amorphous proteins by forming different complex structures at different relative humidities, and demonstrated how this affects the mechanical behavior [41]. To understand the influence of the existence of water in the polyimide film on the properties of the materials, we also studied the mechanical properties of the films after soaking in deionized water for $168 \mathrm{~h}$. The results in Table 4 indicate that the water molecules remaining in the polyimide films had little effect on the mechanical properties of the materials.

Table 4. Mechanical properties of the polyimide films after saturated with water.

\begin{tabular}{cccc}
\hline Sample & Tensile strength/MPa & Elongation at break/\% & Elastic modulus/GPa \\
\hline OPI-water & $134.6 \pm 2.5$ & $13.5 \pm 2.1$ & $3.07 \pm 0.39$ \\
5O5DPI-water & $155.9 \pm 3.9$ & $11.7 \pm 1.9$ & $3.70 \pm 0.37$ \\
DPI-water & $176.0 \pm 3.5$ & $9.6 \pm 1.4$ & $4.27 \pm 0.37$ \\
\hline
\end{tabular}

\subsection{Water Vapor Barrier Properties of the Polyimide Films}

WVTR were measured using a Permeation Test System at $37.8{ }^{\circ} \mathrm{C}$ and $85 \% \mathrm{RH}$, and the results are listed in Table 5. As can be seen, the transmission coefficient and WVTR of OPI is $1.261 \times 10^{-12} \mathrm{~g} \cdot \mathrm{cm} \cdot\left(\mathrm{cm}^{2} \cdot \mathrm{s} \cdot \mathrm{Pa}\right)^{-1}$ and $8.2365 \mathrm{~g} \cdot\left(\mathrm{m}^{2} \cdot 24 \mathrm{~h}\right)^{-1}$, respectively. To our surprise, the WVTR of the polyimide films decreased from $8.2362 \mathrm{~g} \cdot\left(\mathrm{m}^{2} \cdot 24 \mathrm{~h}\right)^{-1}$ (OPI, polyimide without DABA segments) to $0.8670 \mathrm{~g} \cdot\left(\mathrm{m}^{2} \cdot 24 \mathrm{~h}\right)^{-1}$ (DPI, polyimide without ODA segments) with the increase of DABA content. The water vapor barrier properties of the amide-containing polyimide films were improved obviously. Combined with the above experimental results, it suggests that with the increase in the polarity of the polyimide, stronger hydrophilicity of the polymer is more conducive to improving its water vapor barrier properties.

Table 5. Water barrier properties of polyimide films *.

\begin{tabular}{|c|c|c|}
\hline Sample & Transmission coefficient $/ \mathrm{g} \cdot \mathrm{cm} \cdot\left(\mathrm{cm}^{2} \cdot \mathrm{s} \cdot \mathrm{Pa}\right)^{-1}$ & WVTR/g. $\left(\mathrm{m}^{2} \cdot 24 \mathrm{~h}\right)^{-1}$ \\
\hline OPI & $1.261 \times 10^{-12}$ & 8.2365 \\
\hline 7O3DPI & $8.063 \times 10^{-13}$ & 5.2683 \\
\hline 5O5DPI & $5.282 \times 10^{-13}$ & 3.4515 \\
\hline 3O7DPI & $4.923 \times 10^{-13}$ & 3.2167 \\
\hline DPI & $1.327 \times 10^{-13}$ & 0.8670 \\
\hline
\end{tabular}

* Samples are $50 \mu \mathrm{m}$ in thickness, testing at $37.8^{\circ} \mathrm{C}$ and $85 \% \mathrm{RH}$ for $18 \mathrm{~h}$.

\subsection{Mechanism of Water Vapor Barrier Properties of the Polyimides}

The hydration water in a solid medium can be categorized into two types: free water and bound water. The free water almost does not interact with the contact medium, while the bound water is an extremely thin layer of water surrounding the medium surfaces, which has a strong attraction between the surfaces and the water molecules, and is much less mobile than the rest of the water in the medium. According to the distance and the interaction strength between the water molecules and the medium, the bound water can be divided into loosely-bound water and tightly-bound water. At the same time, 
it is also known that in the polymer, the permeation process of gas molecules can be divided into adsorption, diffusion, and desorption steps. Each step is closely related to the interaction between the gas molecules and materials, and has an important effect on the barrier properties of the material. So, this work shows that the nature of the water-polyimide coupled interactions are essential to the water vapor barrier properties of the polyimide.

FT-IR and TGA tests were performed on the DPI films obtained under different treatment conditions. DPI-dried film was obtained by drying the original polyimide film at $300{ }^{\circ} \mathrm{C}$ for $24 \mathrm{~h}$. DPI-water film was obtained by immersing the DPI-dried film into deionized water for $168 \mathrm{~h}$ to make sure the polyimide films were saturated with water. Then, the DPI-water film was dried at $100{ }^{\circ} \mathrm{C}$ for $24 \mathrm{~h}$ to get a DPI-redried film. The results are shown in Figure 6a-c. For the DPI-dried film, there is a very small absorption peak at $3300-3700 \mathrm{~cm}^{-1}$ (Figure 6a), and almost no weight was lost in the temperature range of before $450{ }^{\circ} \mathrm{C}$ as the TGA curves shown in Figure 6b; hence, the absorption peaks should come from the $\mathrm{N}-\mathrm{H}$ stretching vibration of the amide bond in the backbone. The FT-IR spectrum of the DPI-water film exhibited strong absorption peaks at $3627 \mathrm{~cm}^{-1}$ and $3414 \mathrm{~cm}^{-1}$, which is the free hydroxyl stretching vibration and the hydrogen-bonded hydroxyl stretching vibration, respectively, and indicates that both free water and hydrogen-bonded water existed in the DPI-water film. Additionally, as shown in Figure $6 b, c$, all of these water molecules can be completely removed before $215{ }^{\circ} \mathrm{C}$, with a weight loss of about $1.76 \%$. For the DPI-redried film, only the characteristic absorption peak of hydrogen-bonded hydroxyl stretching vibration $\left(3414 \mathrm{~cm}^{-1}\right)$ was observed. The content of this part of water is about $0.65 \%$, which should be the tightly-bound water and can be completely removed before $215^{\circ} \mathrm{C}$ (Figure $6 \mathrm{~b}, \mathrm{c}$ ). These results indicate that the free water molecules can be removed around $100{ }^{\circ} \mathrm{C}$ by evaporation, while the hydrogen-bonded water molecules still existed in the polymer film. This means that after heat treatment at $100{ }^{\circ} \mathrm{C}$ in the vacuum oven, the hydrogen-bonded water remained in the polyimide film. These water molecules are "locked" by forming a strong hydrogen bond interaction with the amide group of the polyimide, and are likely to be removed at a temperature higher than $100{ }^{\circ} \mathrm{C}$ [42-46].
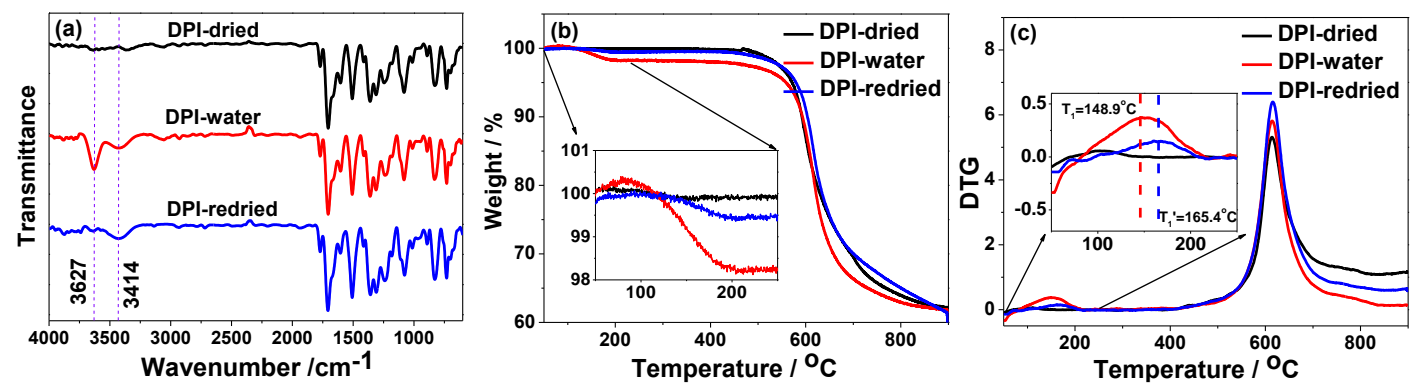

Figure 6. FT-IR spectra and thermogravimetric analysis (TGA) curves of the DPI films under different conditions. (a) FT-IR spectra; (b) TGA curves; (c) Derivative thermogravimetric analysis (DTG) curves.

In order to look further into the weight loss process of the polyimide film in the temperature range of $50-215{ }^{\circ} \mathrm{C}$, the structure of the volatiles was characterized by TG-FTIR. Taking DPI-redried as an example, the results are shown in Figure 7a,b. From the overall FT-IR mapping of the volatile products during the TGA test (Figure 7a), it can be seen that there are two main decomposition processes, which correspond to the TGA results. The FT-IR spectrum of the volatile products at $150{ }^{\circ} \mathrm{C}$ is shown in Figure $7 \mathrm{~b}$. The results are consistent with the standard infrared spectrum of gaseous water (inserted picture in Figure $7 \mathrm{~b}$ ). It is shown that the volatile product in this temperature range is the water component. Usually, water molecules should evaporate at about $100{ }^{\circ} \mathrm{C}$. However, water molecules that interacted with amide groups by hydrogen bonds are more difficult to evaporate; that is, these "locked" water molecules require more energy to escape from the film $[47,48]$, so the evaporation temperature of these water molecules is much higher than $100^{\circ} \mathrm{C}$ and can only be completely removed at about $215^{\circ} \mathrm{C}$. 
To investigate the influence of DABA content on the dehydration temperature of the hydration water in the amide-containing polyimide films, the thermogravimetric behaviors of the saturated water-absorbing polyimide films were studied by TGA, and the results are shown in Figure 8a-e. There are two mass loss processes on the TGA curves. The high-temperature process (above $500{ }^{\circ} \mathrm{C}$ ) corresponds to the thermal decomposition of the polyimide backbone. The mass loss process in the range of $50-400{ }^{\circ} \mathrm{C}$ is closely related to the removal of water molecules in the films according to the TG-FTIR results.
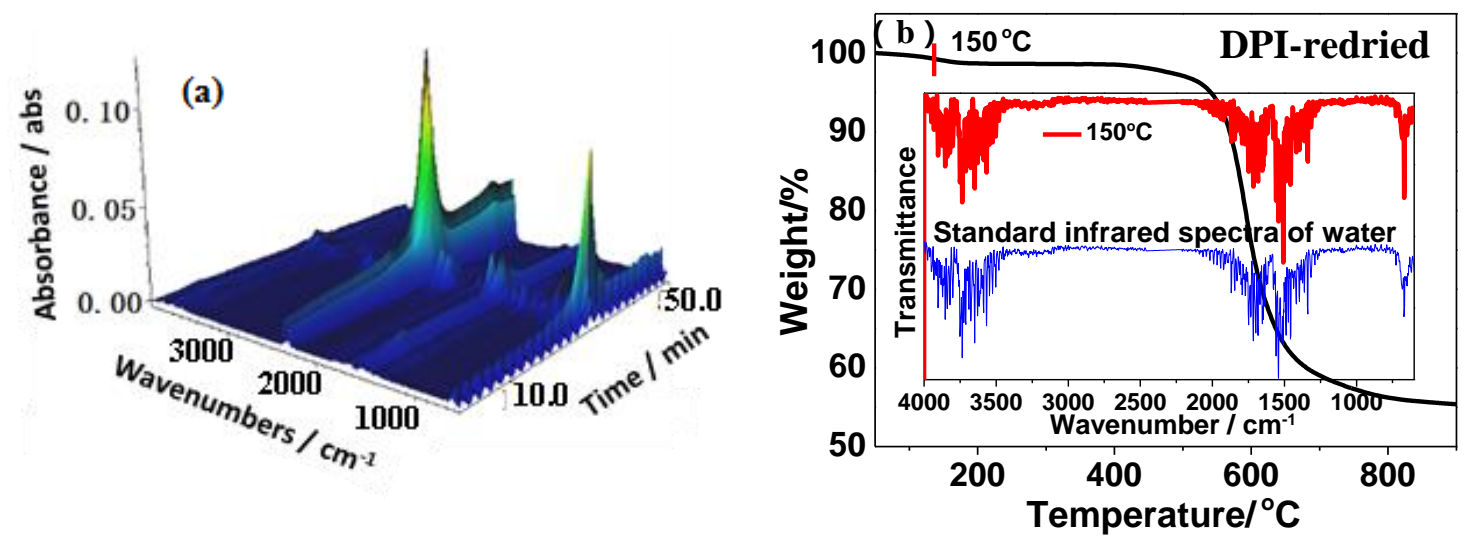

Figure 7. TG-FTIR curves of the DPI-redried film. (a) TG-FTIR curves; (b) FT-IR spectrum of the volatiles at $150{ }^{\circ} \mathrm{C}$.
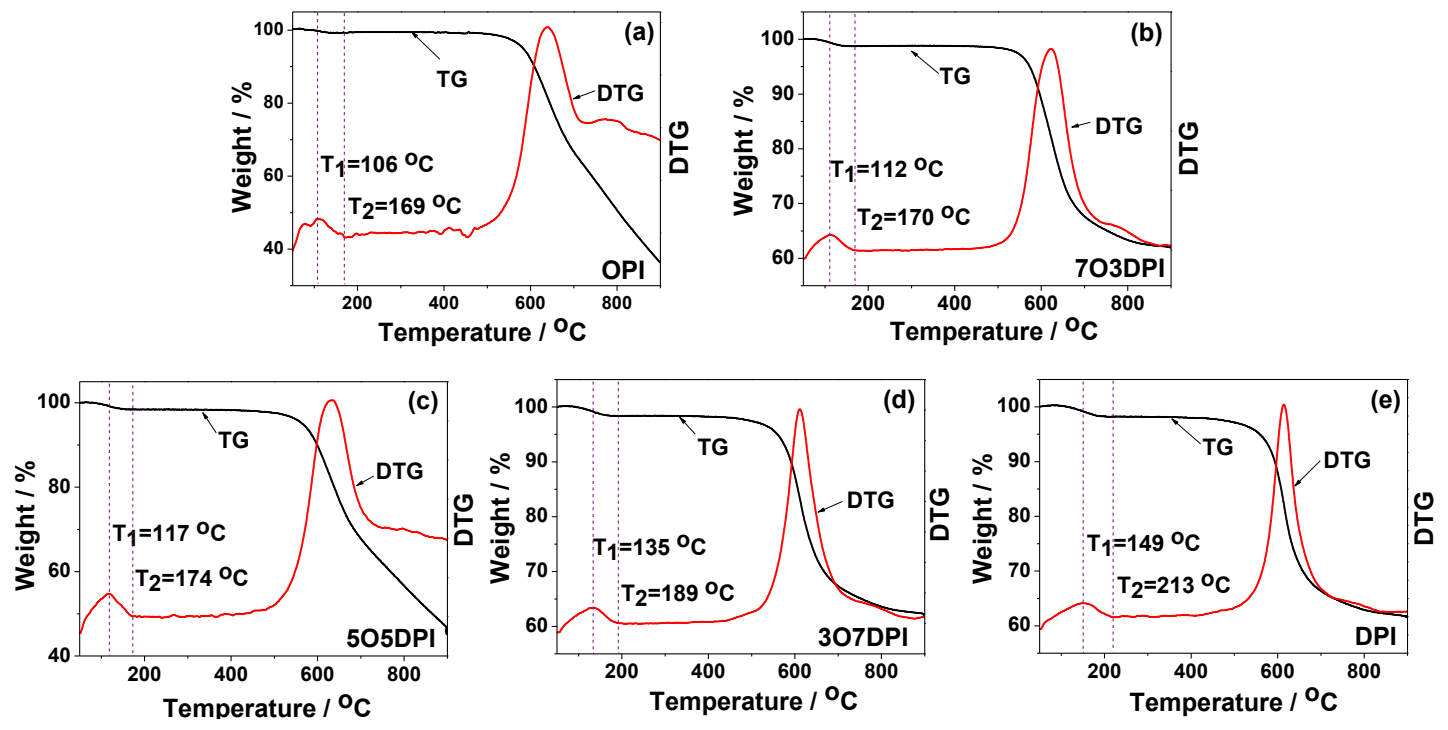

Figure 8. TG and DTG curves of the saturated water-absorbing polyimide films. (a) OPI; (b) 7O3DPI; (c) 5O5DPI; (d) 3O7DPI; (e) DPI.

On the DTG curves, the peak value of the first weight loss peak is labeled as $T_{1}$, which is the temperature of the highest mass lost rate; and $T_{2}$ refers to the temperature when the weight loss ended. For the OPI-water sample, as shown in Figure 7a, the hydrate water was fully removed before $169^{\circ} \mathrm{C}\left(T_{2}\right)$. When $30 \%$ DABA was introduced into the polyimide backbone (7O3DPI), $T_{1}$ was $112{ }^{\circ} \mathrm{C}$, increased by $6{ }^{\circ} \mathrm{C}$, as compared with OPI; while $T_{2}$ remains almost the same. Both $T_{1}$ and $\mathrm{T}_{2}$ were obviously increased with the increase of the DABA content, and finally reached $149^{\circ} \mathrm{C}$ and $213^{\circ} \mathrm{C}$ when all the ODA was replaced by DABA (sample DPI-water), increased by $43^{\circ} \mathrm{C}$ and $44{ }^{\circ} \mathrm{C}$, respectively. At the same time, with the increase of DABA content, the weight loss of water in this system was increased, which is $0.54 \%, 1.15 \%, 1.38 \%, 1.60 \%$, and $1.76 \%$, respectively. These results 
indicate that the hydrogen-bond interactions between water molecules and the amide moieties could "lock" water molecules in the films, and the more amide moieties [49], the more water molecules are locked; meanwhile, the water removal temperature was increased with increasing DABA content.

Based on the above results, the barrier mechanism of the amide-containing polyimides can be proposed, as shown in Figure 9. On one hand, by forming the strong hydrogen bonding intermolecular interaction, the amide groups in the polyimide backbone can improve the orderly arrangement of the polyimide macromolecules, which is beneficial to increase the tight stacking of the molecular chain, thus increasing the density of the polyimide film. On the other hand, the amide groups can interact with water molecules through strong hydrogen bond, so that the penetrated water molecules can be "locked" in the films, and their diffusion in the film would be greatly limited; the "locked" water molecules can also form hydrogen bonds with other water molecules. These "locked" water molecules may form certain "water clusters" in the film, which needs to be further confirmed by some direct experimental methods such as neutron scattering. The "locked" water molecules in the film may further decrease the free volume of the polymer, and thus help to improve the WVTR property of the materials.
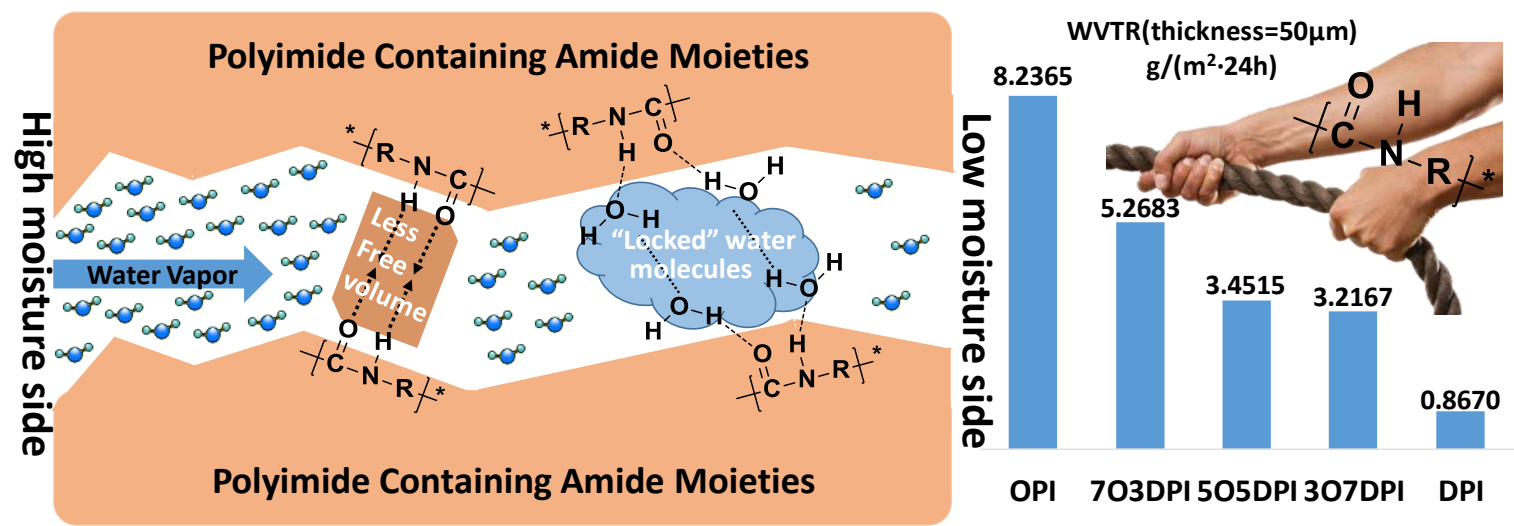

Figure 9. The barrier mechanism of the amide-containing polyimide films.

In order to further verify the mechanism proposed above, WVTR measurements were performed on DPI samples (diameter of $1.2 \mathrm{~cm}$ and thickness of $45 \mu \mathrm{m}$ ) for $72 \mathrm{~h}$ under different pretreatment or test conditions. The DPI-dried film was obtained by drying the polyimide film at $300{ }^{\circ} \mathrm{C}$ for $24 \mathrm{~h}$ to ensure it was dried completely. WVTR test was carried out at $37.8{ }^{\circ} \mathrm{C}$ and $85 \%$ humidity, and the results are shown in Figure 10. With the increase of testing time, the WVTR showed a trend of increasing first and then decreasing (black line in Figure 10). The WVTR reached the highest value of $1.083 \mathrm{~g} \cdot\left(\mathrm{m}^{2} \cdot 24 \mathrm{~h}\right)^{-1}$ when the testing time was $4 \mathrm{~h}$, and then the WVTR fell steadily, finally stable at around $0.6000 \mathrm{~g} \cdot\left(\mathrm{m}^{2} \cdot 24 \mathrm{~h}\right)^{-1}$ after the testing time was greater than $48 \mathrm{~h}$. This phenomenon can be interpreted as follows. At the very beginning, the WVTR is at a relatively high level. As the test progressed, the water vapor molecules continued to penetrate into the interior of the film, and were "locked" in the film by forming strong hydrogen bond interactions with the amide bond on the macromolecular chain. The water molecules entering later may also form hydrogen bond with the "locked" water molecules, filling the voids (also known as free volume) inside the polymer film. The existence of these "locked" water molecules will prevent the further diffusion process of water molecules in the film, thus making the penetration or diffusion of the water molecules increasingly difficult. As a result, the WVTR of the polyimide film is continuously lowered, and the barrier property thereof is improved. 


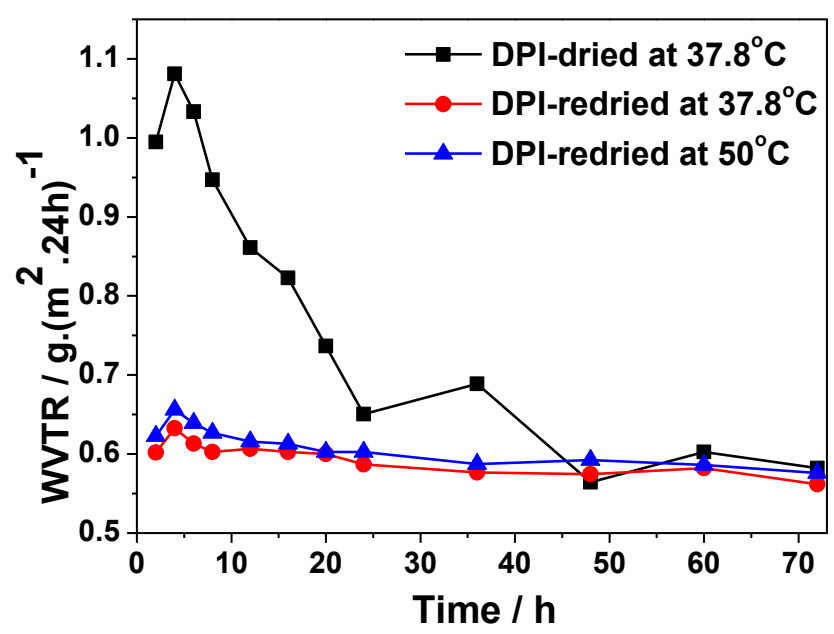

Figure 10. Water barrier property of DPI films ( $45 \mu \mathrm{m}$ in thickness, testing at $85 \% \mathrm{RH}$ for $72 \mathrm{~h})$.

The effect of the tightly-bound water molecules on the water vapor barrier properties of the polyimide films can be further verified by the WVTR test results of the DPI-redried film. The sample was obtained by drying the water-saturated DPI film in a $100{ }^{\circ} \mathrm{C}$ vacuum oven, and it has been determined that there was about $0.65 \%$ of tightly-bound water in the film (Figure 6). The WVTR testing condition was also at $37.8{ }^{\circ} \mathrm{C}$ and $85 \%$ humidity, and the results are shown in Figure 10 (red line). Compared with the DPI-dried sample (black line), the barrier property of the DPI-redried sample was more stable during the test and the WVTR values were maintained at a relatively lower level, which is about $0.6000 \mathrm{~g} \cdot\left(\mathrm{m}^{2} \cdot 24 \mathrm{~h}\right)^{-1}$-almost the same as that of the DPI-dried sample after $48 \mathrm{~h}$ testing. More importantly, such good water vapor barrier properties are stable at a higher temperature, as shown by the blue line in Figure 10, which was measured at $50{ }^{\circ} \mathrm{C}$ (the highest testing temperature of the equipment) and $85 \% \mathrm{RH}$ for $72 \mathrm{~h}$.

\section{Conclusions}

In summary, an interesting and novel approach was shown to improve the water vapor barrier property of polymer materials by introducing a typical polar group (amide group) into the polymer backbone, and a so-called "locked-water effect" was proposed to illuminate the mechanism. Our results showed that the existence of the amide groups in the polymer main chain played an important role in the WVTR property in two aspects. On the one hand, the formation of inter-molecular hydrogen bond interactions among the amide groups is beneficial to form a more ordered and compact aggregation structure. On the other hand, the amide groups can form strong hydrogen bond interactions with the water vapor molecules, preventing their diffusion by "locking" them in the film, these "locked" water molecules in the film may further decrease the free volume of the polymer, and thus help to improve the WVTR property of the materials. By this means, the WVTR value of the polyimide films can be decreased by an order of magnitude, from $8.2362 \mathrm{~g} \cdot\left(\mathrm{m}^{2} \cdot 24 \mathrm{~h}\right)^{-1}$ to $0.8670 \mathrm{~g} \cdot\left(\mathrm{m}^{2} \cdot 24 \mathrm{~h}\right)^{-1}$.

Acknowledgments: The financial support by the Science and Technology Project of Guangdong Province (Nos. 2015B090915003 and 2015B090913003), the National 973 Program of China (No. 2014CB643605), the National Natural Science Foundation of China (Nos. 51373204, 51173214 and 51233008), the National 863 Program of China (No. 2015AA033408), the Leading Scientific, Technical and Innovation Talents of Guangdong Special Support Program (No. 2016TX03C295), and the Fundamental Research Funds for the Central Universities (No. 161gzd08) are gratefully acknowledged.

Author Contributions: Kai Zhang, Yi Zhang and Jiarui Xu conceived and designed the experiments; Kai Zhang, Qiaoxi Yu and Longji Zhu performed the experiments; Kai Zhang, Siwei Liu, Zhenguo Chi, Xudong Chen, Yi Zhang and Jiarui Xu analyzed the data; Kai Zhang, Yi Zhang and Jiarui Xu wrote the paper.

Conflicts of Interest: The authors declare no conflict of interest. 


\section{References}

1. Harper, C.A. Electronic Materials and Processes Handbook, 3rd ed.; McGraw-Hi: New York, NY, USA, 2005; ISBN 9780071402149.

2. Milek, J.T. Polyimide Plastic Technology: A State-of-the-Art Report; Electronic Properties Information Centre, Hughes Aircraft: Culver City, CA, USA, 1965.

3. Saba, N.; Tahir, P.M.; Jawaid, M. A Review on potentiality of nano filler/natural fiber filled polymer hybrid composites. Polymers 2014, 6, 2247-2273. [CrossRef]

4. Ghosh, M.K.; Mittal, K.L. Polyimides: Fundementals and Applications; Mercel Dekker: New York, NY, USA, 1996; ISBN 0824794664.

5. Siqueira, G.; Bras, J.; Dufresne, A. Cellulosic Bionanocomposites: A review of preparation, properties and applications. Polymers 2010, 2, 728-765. [CrossRef]

6. Wang, W.Y.; Hui, P.; Wat, E. Enhanced transdermal permeability via constructing the porous structure of poloxamer-based hydrogel. Polymers 2016, 8, 406. [CrossRef]

7. Yucel, O.; Unsal, E.; Harvey, J. Enhanced gas barrier and mechanical properties in organoclay reinforced multi-layer poly(amide-imide) nanocomposite film. Polymer 2014, 55, 4091-4101. [CrossRef]

8. Zhou, L.Z. Microelectronic Device Package-Packaging Materials and Packaging Technology; Chemical Industry Press: Beijing, China, 2006; pp. 7-10. ISBN 9787502590376.

9. Hocker, S.; Smith, N.H.; Schniepp, H.C. Enhancing polyimide's water barrier properties through addition of functionalized graphene oxide. Polymer 2016, 93, 23-29. [CrossRef]

10. Zhang, J.W.; Zhang, G.P.; Sun, R. Research progress of encapsulation materials for OLED. J. Integr. Technol. 2014, 3, 92-101.

11. Schmid, M.; Saengerlaub, S.; Miesbauer, O. Water repellence and oxygen and water vapor barrier of PVOH-coated substrates before and after surface esterification. Polymers 2014, 6, 2764-2783. [CrossRef]

12. Ghoshal, S.; Denner, P. Study of the Formation of poly(vinyl alcohol) Films. Macromolecules 2012, 45, 1913-1923. [CrossRef]

13. Fotie, G.; Rampazzo, R.; Ortenzi, M.A. The effect of moisture on cellulose nanocrystals intended as a high gas barrier coating on flexible packaging materials. Polymers 2017, 9, 415. [CrossRef]

14. Zhu, T.J. Measurement of the Permeability of Water Vapor through OLED Encapsulation. Master's Thesis, University of Electronic Science and Technology of China, Chengdu, China, 2006.

15. Huang, H.Y.; Huang, T.C.; Yeh, T.C. Advanced anticorrosive materials prepared from amine-capped aniline trimer-based electroactive polyimide-clay nanocomposite materials with synergistic effects of redox catalytic capability and gas barrier properties. Polymer 2011, 52, 2391-2400. [CrossRef]

16. Wang, Y.Z. Vacuum Technology; Beihang University Press: Beijing, China, 2007; ISBN 9787810779548.

17. Gómez, M.; Palza, H.; Quijada, R. Influence of organically-modified montmorillonite and synthesized layered silica nanoparticles on the properties of polypropylene and polyamide- 6 nanocomposites. Polymers 2016, 8, 386. [CrossRef]

18. Nilsen-Nygaard, J.; Strand, S.; Vårum, K. Chitosan: Gels and interfacial properties. Polymers 2015, 7, 552-579. [CrossRef]

19. Liang, Q.; Zhou, H.P.; Fu, R.L. Themal conductivity of AlN ceramicssintered with $\mathrm{CaF}_{2}$ and $\mathrm{YF}_{3}$. CtronSystSector 2004, 2, 648-653.

20. Vaed, K.; Florkey, J.; Akbar, S.A. An additive micro-molding approach for the development of micro-machined ceramic substrates for RF applications. J. Microelectron. Mech. Syst. 2004, 30, 514-525. [CrossRef]

21. Bandera, D.; Meyer, V.R.; Prevost, D. Polylactide/montmorillonite hybrid latex as a barrier coating for paper applications. Polymers 2016, 8, 75. [CrossRef]

22. Chee, W.K.; Lim, H.N.; Huang, N.M. Nanocomposites of graphene/polymers: A review. RSC Adv. 2015, 5, 68014-68051. [CrossRef]

23. Aldana, D.S.; Villa, E.D.; De Dios Hernández, M.; Sánchez, G.G.; Cruz, Q.R.; Gallardo, S.F.; Castillo, H.P.; Casarrubias, L.B. Barrier properties of polylactic acid in cellulose based packages using montmorillonite as filler. Polymers 2014, 6, 2386-2403. [CrossRef] 
24. Gaska, K.; Kádár, R.; Rybak, A. Gas Barrier, Thermal, mechanical and rheological properties of highly aligned graphene-LDPE nanocomposites. Polymers 2017, 9, 294. [CrossRef]

25. Li, X.L.; Ma, H.A.; Zuo, G.H. Low temperature sintering of high density aluminium nitride ceramics without additives at high pressure. Scipta Mater. 2007, 56, 1015-1018. [CrossRef]

26. Ge, J.J.; Li, C.Y.; Xue, G.; Mann, I.K.; Zhang, D.; Harris, F.W.; Cheng, S.Z.D.; Hong, S.C.; Zhuang, X.; Shen, Y.R. Rubbing-Induced Molecular Reorientation on an Alignment Surface of an Aromatic Polyimide Containing Cyanobiphenyl Side Chains. J. Am. Chem. Soc. 2001, 123, 5768-5776. [CrossRef] [PubMed]

27. Lim, H.; Cho, W.J.; Ha, C.S.; Ando, S.; Kim, Y.K.; Park, C.H.; Lee, K. Flexible organic electroluminescent devices based on fluorine-containing volorless polyimide substrates. Adv. Mater. 2002, 14, 1275-1279. [CrossRef]

28. Liu, Y.W.; Qian, C.; Qu, L.J.; Wu, Y.N.; Zhang, Y.; Wu, X.H.; Zou, B.; Chen, W.X.; Chen, Z.Q.; Chi, Z.G.; et al. A bulk dielectric polymer film with intrinsic ultralow dielectric constant and outstanding comprehensive properties. Chem. Mater. 2015, 27, 6543-6549. [CrossRef]

29. Buntinx, M.; Willems, G.; Knockaert, G. Evaluation of the thickness and oxygen transmission rate before and after thermoforming mono- and multi-layer sheets into trays with variable depth. Polymers 2014, 6, 3019-3043. [CrossRef]

30. Larson, S.E.; Slaby, J. Comparison of various substrate technologies under steady state and transient conditions. In Proceedings of the Thermal and Thermomechanical Phenomena in Electronic Systems, Las Vegas, NV, USA, 1-4 June 2004. [CrossRef]

31. Liu, Q.J.; Li, X.Y.; Chen, G.W. Research and application progress on barrier polymer composites. Plast. Sci. Technol. 2013, 41, 104-108.

32. Sehaqui, H.; Kochumalayil, J.; Liu, A. Multifunctional nanoclay hybrids of high toughness, thermal, and barrier performances. ACS Appl. Mater. Interface 2013, 5, 7613-7620. [CrossRef] [PubMed]

33. Ding, Y.S.; Zhang, Z.C.; Shi, T.J. Application of biodegradable polyhydroxybutyrate in tissue engineering. J. Funct. Polym. 2001, 3, 361-364.

34. Li, S.L. Measurement of Gas Permeability of OLED Packaging Materials. Master's Thesis, University of Electronic Science and Technology of China, Chengdu, China, 2009.

35. Huang, W.D. Research on Moisture-Proof Film Technology in High Reliability Electronic Package. Ph.D. Thesis, Shanghai Institute of Microsystem and Information Technology, Shanghai, China, 2003.

36. Park, J.S.; Chae, H.; Chung, H.K. Thin film encapsulation for flexible AM-OLED: A review. Semicond. Sci. Technol. 2011, 26, 034001. [CrossRef]

37. Massey, L.K. Permeability Properties of Plastics and Elastomers: A Guide to Packaging and Barrier Materials/Plastics Design Library; William Andrew: New York, NY, USA, 2003; ISBN 1884207979.

38. Ping, Z.H.; Nguyen, Q.T.; Chen, S.M. States of water in different hydrophilic polymers-DSC and FTIR studies. Polymer 2001, 42, 8461-8467. [CrossRef]

39. Yucel, O.; Unsal, E.; Cakmak, M. Temporal evolution of optical gradients during drying in cast polymer solutions. Macromolecules 2013, 46, 7112-7117. [CrossRef]

40. Unsal, E.; Drum, J.; Yucel, O. Real-time measurement system for tracking birefringence, weight, thickness, and surface temperature during drying of solution cast coatings and films. Rev. Sci. Instrum. 2012, 83, 352. [CrossRef] [PubMed]

41. Yu, S.; Chen, F.; Hedenqvist, M.S. Structural Changes of Gluten/Glycerol Plastics under Dry and Moist Conditions and during Tensile Tests. ACS Sustain. Chem. Eng. 2016, 4, 3388-3397. [CrossRef]

42. Hyoe, H.; Tatsuko, H. Interaction between water and hydrophilic polymers. Thermochim. Acta 1998, 308, 3-22. [CrossRef]

43. Nelson, R. The determination of moisture transitions in cellulosic materials using differential scanning calorimetry. J. Appl. Polym. Sci. 1977, 21, 645-654. [CrossRef]

44. Ye, Y.S.; Rick, J.; Hwang, B.J. Water soluble polymers as proton exchange membranes for fuel cells. Polymers 2012, 4, 913-963. [CrossRef]

45. Kadajji, V.G.; Betageri, G.V. Water soluble polymers for pharmaceutical applications. Polymers 2011, 3 , 1972-2009. [CrossRef] 
46. Nakamura, K.; Hatakeyama, T.; Hatakeyama, H. Studies on bound water of celluslose by different scanning calorimetry. Text. Res. J. 1981, 51, 607. [CrossRef]

47. Magne, E.C.; Portas, H.J.; Wakeham, H.A. Design and analysis of the homogeneous and heterogeneous distribution of water confined within colloidal polymer particles. Colloid Polym. Sci. 2013, 291, 143-156. [CrossRef]

48. Hatakeyama, H.; Hatakeyama, T.M. Phase transition temperature of water restrained in polysulfone hollow fibres. J. Therm. Anal. 1993, 40, 727-733. [CrossRef]

49. Miltner, H.E.; Assche, G.V.; Pozsgay, A. Restricted chain segment mobility in poly(amide) 6/clay nanocomposites evidenced by quasi-isothermal crystallization. Polymer 2006, 47, 826-835. [CrossRef]

2017 by the authors. Licensee MDPI, Basel, Switzerland. This article is an open access article distributed under the terms and conditions of the Creative Commons Attribution (CC BY) license (http://creativecommons.org/licenses/by/4.0/). 